\title{
Trace Determination of Boron in Uranium-Aluminum- Silicon and Aluminum-Silicon-Nickel (SILUMIN) Alloys by Inductively Coupled Plasma Atomic Emission Spectrometry (ICP-AES)
}

\author{
S. Thangavel, K. Dash, S.M. Dhavile, S.C. Chaurasia, and J. Arunachalam* \\ National Centre for Compositional Characterisation of Materials \\ Bhabha Atomic Research Centre, Hyderabad 500062, India
}

\section{INTRODUCTION}

Boron is a critical element in materials used in the nuclear power industry because of its high neutron absorption cross-section. The requirements on structural materials for nuclear reactor cores are very stringent due to special features of their operation. The main requirements imposed on such materials include low capture crosssection for neutrons, corrosion and erosion resistance in coolant, radiation resistance, and high thermal conductivity (1). Among the elements with low neutron absorption cross-section, aluminum and its alloys are primarily used for fuel element claddings, process channel pipes of commercial and research reactors $(1,2)$. The corrosion behavior of aluminum-clad fuels in light water reactor environments was improved by the use of SILUMIN (aluminum-silicon alloy) (3). This alloy has a number of remarkable technological and operational properties (4). Boron is used in aluminum alloys for certain atomic energy applications, but its content has to be restricted to very low levels in alloys used in reactor areas (5). Another important material used in the nuclear industry is uranium-aluminum-silicon alloy, which is used in thermal reactors, test reactors, and nuclear submarines $(6,7)$. Satisfactory power output and neutron flux distribution of the reactor requires control of both

\footnotetext{
* Corresponding autbor.

E-mail: thangcccm@rediffmail.com

Tel.: +91040 27121365

Fax: +9104027125463
}

\begin{abstract}
A novel and simple matrix separation method has been developed for the trace level determination of boron in uranium-aluminum-silicon and aluminum-silicon-nickel (SILUMIN) alloys using inductively coupled plasma atomic emission spectrometry (ICP-AES). The samples were digested by $\mathrm{HF} / \mathrm{HF}-\mathrm{HNO}_{3}$ in the presence of mannitol to form the boron-mannitol complex. The sample solution was evaporated to dryness on a water bath and treated with ethanol to selectively extract the boron-mannitol complex from the solid residue of the matrix. The ethanol fraction containing the boron-mannitol complex was separated, evaporated to dryness, taken in water, and measured by ICP-AES. The limit of detection was found to be $0.270 \mathrm{mg} \mathrm{kg}^{-1}$. The matrix removal was around $99.5 \%$, the recovery of boron for 80-450 ng was in the $93-96 \%$ range. The analytical results of boron in U-Al-Si matrices (0.40-1.10 $\left.\mathrm{mg} \mathrm{kg}^{-1}\right)$ agreed well with existing spectrophotometric methods at $\pm 4 \%$ variation.
\end{abstract}

total boron content and boron distribution in the fuel (2). Hence, it is essential to develop a simple, accurate, and precise method for the determination of traces of boron in both of these alloys.

Several analytical methods have been reported for the determination of boron in various types of matrices (8-11). Among these, all destructive methods invariably require matrix separation for trace level determination of boron. Inductively coupled plasma atomic emission spectrometry (ICP-AES) is routinely used in most of the laboratories for analyzing many elements in different matrices. The major problems encountered in the trace determination of boron in uranium and aluminum matrices using ICP-AES are the strong spectral interferences for boron lines $(5,12$, 13) and dilution of the sample solution to minimize the spectral interference which leads to a high limit of detection. Solvent extraction $(14,15)$ and methyl borate distillation $(16,17)$ methods are commonly employed for the separation of boron in different types of matrices. Hydrofluoric acid is required for the dissolution of SILUMIN and U-Al-Si matrices. The solvent extraction method for the separation of boron in HF medium involves the extraction of tetrafluoroborate as its ion association complex with organic cations into immiscible organic solvents followed by spectrophotometric determination (18). This separation method cannot be applied for ICP-AES determination due to the extraction of HF (19) and the ion-associated boron complex present in the organic solvent. Distillation of the methyl borate method is also not suitable in the presence of hydrofluoric acid because the fluoride ion prevents the distillation of borate ester (18).

It is widely known that boric acid reacts with mannitol to form the boron-mannitol complex. This complex suppresses the volatiliza- 
tion of boron from HF-containing solutions, where the digested (volatile) matrix is evaporated at $\sim 90{ }^{\circ} \mathrm{C}$, and the boron-mannitol complex is left behind as a solid residue $(20,21)$. This method has been applied to the determination of boron in silicate rock and quartz samples $(22,23)$. However, this method cannot be applied to nonvolatile matrices. For these matrices, it is essential to extract the boron-mannitol complex from the matrix and hydrofluoric acid. To the best of our knowledge, no published literature exists for the extraction of the boron-mannitol complex.

In addition, no method has been reported in the literature for the determination of boron in SILUMIN alloy. In the reported method by Ramanjaneyulu et al. (7), boron was determined in U-Al-Si alloy using leaching of boron, followed by spectrophotometric measurement. However, in this method, the sample dissolution could not be carried out due to the potential interference of the fluoride ion (HF is required for dissolution of the sample) using curcumin. Recently, this curcumin method was applied to the determination of traces of boron in $\mathrm{U}_{3} \mathrm{O}_{8}$ after matrix separation using solvent extraction (24). Since nitric acid is required for the dissolution of the sample, the authors studied the potential interference of the nitrate ion in this spectrophotometric method. For SILUMIN and U-AlSi alloys, $\mathrm{HF}$ and $\mathrm{HNO}_{3}$ are required for the complete dissolution of these matrices. The nitrate and fluoride ions are interfered strongly in the spectrophotometric method using curcumin (9). Hence, it is essential to develop an alternate analytical technique for the measurement of traces of boron in these alloys.

In this work, we developed a simple matrix separation method, followed by ICP-AES measurement.
After dissolving the samples by $\mathrm{HF}$ and $\mathrm{HNO}_{3}$, the analyte was separated from the matrix through selective extraction of boron as boron-mannitol complex using ethanol.

\section{EXPERIMENTAL}

\section{Instrumentation}

A Model JY-2000 ICP-AES (JobinYvon, France) sequential spectrometer was used for this study. The specification and operating conditions are listed in Table I. The integration time was 0.5 seconds and background correction was carried out by subtracting the background (at $0.04 \mathrm{~nm}$ away on either side from the $\lambda_{\max }$ ) from the analyte signal.

\section{Reagents and Standard Solutions}

The reagents used were $\mathrm{HF}$ (40\%) Suprapur ${ }^{\circledR}$ grade, (E. Merck, Darmstadt, Germany; $\mathrm{HNO}_{3}$ (69\%) G.R. grade and D-Mannitol (pure grade) (E. Merck, India); ethyl alcohol 99.9\% (v/v) A.R. grade (Hayman Ltd., England). High purity $(0.05 \mu \mathrm{S} / \mathrm{cm})$ water was prepared by passing potable water through a deionization system and then through a Milli- ${ }^{\mathrm{TM}}$ system (Millipore Corporation, Bedford, MA, USA). Boron standard solutions used for calibration were prepared from single-element ICP-AES stock solutions (E. Merck, Germany) containing $1 \mathrm{mg} \mathrm{ml}^{-1}$ of boron.

TABLE I

ICP-AES Instrumental and Operating Conditions

\begin{tabular}{|c|c|}
\hline Monochromator & Horiba Jobin-Yvon 2000 ICP-AES \\
\hline Mounting & Czerny-Turner, focal length $0.64 \mathrm{~m}$ \\
\hline Grating & Holographic, 2400 grooves $\mathrm{mm}^{-1}$ \\
\hline Wavelength range & $160-800 \mathrm{~nm}$ \\
\hline Spectral band width & $13 \mathrm{pm}$ \\
\hline Detector & Photomultiplier (PMT) \\
\hline Rf generator & Solid state RF $40.68 \mathrm{MHz}$ \\
\hline Frequency & $40.68 \mathrm{MHz}$ \\
\hline Power output & $0.5-1.55 \mathrm{~kW}$ \\
\hline Nebulizer & Meinhard, concentric glass \\
\hline Spray chamber & JY Glass cyclonic spray chamber \\
\hline Plasma torch & Fully demountable torch \\
\hline Injector tube diameter of torch & $3 \mathrm{~mm}$ \\
\hline Pump & Peristaltic, 12-roller (JY, France) \\
\hline \multicolumn{2}{|c|}{ Operating conditions of ICP-AES } \\
\hline Incident power & $1.0 \mathrm{~kW}$ \\
\hline Outer argon flow rate & $13 \mathrm{~L} \mathrm{~min}^{-1}$ \\
\hline Auxiliary gas & $0 \mathrm{~L} \mathrm{~min} \operatorname{mon}^{-1}$ \\
\hline Sheath gas flow rate & $0 \mathrm{~L} \min ^{-1}$ \\
\hline Carrier gas flow rate & $0.4 \mathrm{~L} \mathrm{~min}^{-1}$ \\
\hline Liquid uptake rate & $1.2 \mathrm{~mL} \mathrm{~min}^{-1}$ \\
\hline Nebulizer pressure & 2.7 bar \\
\hline
\end{tabular}




\section{Procedure}

For the analysis of U-Al-Si alloy, $0.2 \mathrm{~g}$ of sample and $4 \mathrm{~mL}$ of $1 \%$ (w/v) mannitol solution were taken into a PTFE container $(\sim 20 \mathrm{~mL}$ capacity) and $2 \mathrm{~mL}$ of $22 \mathrm{M} \mathrm{HF}$ was added drop by drop to prevent rapid decomposition of the sample. After complete dissolution of the sample, the sample solution was evaporated to dryness over a water bath $\left(\sim 90^{\circ} \mathrm{C}\right)$. The dried sample residue was treated with $\sim 4 \mathrm{~mL}$ of ethanol, closed tightly, and heated over the water bath $\left(\sim 90^{\circ} \mathrm{C}\right)$ for 30 minutes to extract the boronmannitol complex from the sample residues to ethanol. The PTFE container was allowed to cool to room temperature and the ethanol fraction carefully pipetted into another clean PTFE container $(\sim 5 \mathrm{~mL}$ capacity) using a micropipette of $1 \mathrm{~mL}$ capacity. Then $1 \mathrm{~mL}$ of $1 \%(\mathrm{w} / \mathrm{v})$ mannitol solution was added to the extracted ethanol fraction and dried over the water bath $\left(\sim 90^{\circ} \mathrm{C}\right)$. The dried residue of mannitol with boron-mannitol complex was dissolved in $3.0 \mathrm{~mL}$ of high purity water and the boron content measured by ICP-AES using the instrumental parameters as listed in Table I. The standard solutions were prepared after the required dilution of the stock solution using high purity water. The calibration graph for boron was plotted using the standard solutions in the range of $0.05-0.50 \mathrm{mg} \mathrm{L}^{-1}$.

For the analysis of SILUMIN, sample dissolution was carried out as described in the dissolution of U-Al-Si alloy. After treatment with $\mathrm{HF}, 0.5 \mathrm{~mL}$ of $\mathrm{HNO}_{3}$ was added dropwise for complete dissolution of the sample. Again, $1.0 \mathrm{~mL}$ of $1 \%$ (w/v) mannitol was added to the sample solution and evaporated to dryness over the water bath. The remaining sample preparation procedure was similar to that adopted for the analysis of U-Al-Si alloy.

\section{RESULTS AND DISCUSSION}

\section{Determination of Boron in the Presence of Matrix Elements (U-Al-Si and SILUMIN) by Direct ICP-AES}

The major elements in the U-AlSi (U: 72-74\%, Al: 22-25\%, Si: 2.73.5\%) and SILUMIN (Al: 84-86\%, Si: $11-13 \%, \mathrm{Ni}: 2 \%$ ) alloys were about $3 \times 10^{5}-2.5 \times 10^{6}$ times higher than the level of boron. The effect of the intensity of the emission lines due to the matrix elements in both alloys at their concentration of $0.005-5.0 \mathrm{mg} \mathrm{mL}^{-1}$ for $0.4 \mathrm{mg} \mathrm{L}^{-1}$ of boron was studied. The intensity of the emission for boron increased as the amount of alloys increased. The emission intensity by alloys alone was observed and showed a similar increase as that of boron with alloys. The emission intensity for boron alone was determined by subtracting the emission intensity for alloys alone from that of alloy with boron, which was found to decrease as the concentrations of the alloys were increased. This may be due to multiplicative interferences related to sensitivity changes in the analyte signal, so that the signal-to-background ratio is modified. The net decrease in analyte signal was significant when the concentrations of the alloys were more than 0.1 and $0.3 \mathrm{mg} \mathrm{mL}^{-1}$ for U-Al-Si and SILUMIN, respectively. The study shows that in both cases matrix separation was essential to determine the trace levels of boron accurately by direct ICP-AES. After separation of the matrix (200 $\mathrm{mg}$ of sample was made up to $3 \mathrm{~mL}$ volume), the concentrations of the matrix elements in the sample solution passing into the ICP-AES were well below their tolerance levels ( $<0.1$ and $<0.3 \mathrm{mg} \mathrm{mL}^{-1}$ for U-Al-Si and SILUMIN, respectively).

\section{Optimization of Sample Dissolution}

A vigorous reaction takes place during dissolution of the samples with hydrofluoric acid. Therefore, the sample was taken in water and HF was added drop by drop to prevent rapid dissolution of the sample. Even in this case, due to the generation of heat during the addition of HF, the volatilization of boron during sample dissolution was studied. For both matrices, $100 \mu \mathrm{g}$ of boron was added to the sample (taken in water), dissolved by the addition of $22 \mathrm{M} \mathrm{HF}$, and the recovery study carried out prior to matrix separation. Since large amounts of boron were added, the sample solution was diluted to $1000 \mathrm{~mL}$ to minimize spectral interference by the matrix elements on the analytical wavelength of boron. The recovery in both matrices was $\sim 60 \%$. Therefore, the sample was taken in mannitol solution (1\%, w/v), and HF was added dropwise to the sample to prevent volatilization of boron. The recovery improved up to $\sim 98 \%$. The complete sample dissolution with quantitative recovery was optimized as follows: the sample $(0.2 \mathrm{~g})$ was taken in $4 \mathrm{~mL}$ of $1 \%(\mathrm{w} / \mathrm{v})$ mannitol solution and $2 \mathrm{~mL}$ of $\mathrm{HF}(40 \%, \mathrm{w} / \mathrm{v})$ was added to the sample. For SILUMIN, after dissolution of the sample, an additional $1 \mathrm{~mL}$ of $1 \%$ mannitol was added prior to the evaporation of the sample solution.

\section{Suppression of Volatilization of Boron During Evaporation of Sample Solution}

After dissolution of the samples, both matrices were dried over a water bath and a recovery study was carried out to establish any loss of boron during evaporation of the sample solution. Even though quantitative recovery was found in U-AlSi alloy, in the case of SILUMIN the recovery was only $\sim 35 \%$. This is probably due to the degradation of mannitol during treatment of the 


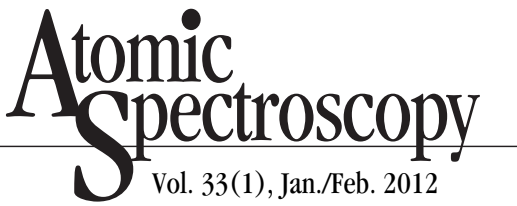

sample with $\mathrm{HNO}_{3}$ (11). Hence, in the case of SILUMIN, after treatment with $\mathrm{HNO}_{3}$, an additional $1 \mathrm{~mL}$ of $1 \%$ mannitol was added to the sample solution prior to its evaporation. This step improved the recovery up to $\sim 96 \%$.

In the preliminary experiments, after the extraction of the boronmannitol complex, the ethanol fraction was dried over a water bath, but the recovery was only $\sim 20 \%$. This low recovery of boron may be due to the formation of volatile borate ester, which is lost during the evaporation of ethanol, as reported earlier (7).

$\mathrm{H}_{3} \mathrm{BO}_{3}+3 \mathrm{C}_{2} \mathrm{H}_{5} \mathrm{OH} \leftrightarrow \mathrm{B}\left(\mathrm{OC}_{2} \mathrm{H}_{5}\right)_{3}+3 \mathrm{H}_{2} \mathrm{O}$

To prevent the formation of borate ester, $1 \mathrm{~mL}$ of $1 \%$ mannitol solution was added prior to the evaporation of the ethanol fraction. Now the recovery was improved to $\sim 94 \%$. This shows that the mannitol extracted along with the boronmannitol complex by ethanol may not be sufficient to suppress the volatilization of boron completely.

\section{The Efficiency of Matrix Removal and Extraction of Boron-Mannitol Complex}

After dissolution of the sample, the sample solution was dried over a water bath $\left(\sim 90^{\circ} \mathrm{C}\right)$. The dried sample residue, which contains the boron-mannitol complex, was extracted into ethanol over the water bath $\left(\sim 90^{\circ} \mathrm{C}\right)$. The sample solution should be completely dry, otherwise the matrix elements dissolve into ethanol and the ethanol becomes turbid.

The effect of the presence of water in the sample residue was studied by adding various amounts of water into the dried sample residue, and the extraction was carried out. Even in the presence of $0.2 \mathrm{~mL}$ of water, the ethanol solution becomes turbid. Hence, the sample solution needs to be centrifuged to obtain a clear solution prior to ICP-AES measurements. In this case, the recovery of boron was found to be poor and when the fraction of water was increased, the recovery of boron decreased (Figure 1). This could be due to the co-precipitation of boron fluoride along with the uranium/aluminum fluoride precipitate.

Figure 2 shows that the time required for quantitative ( $95 \%)$ extraction of the boron-mannitol complex in ethanol on a water bath $\left(\sim 90^{\circ} \mathrm{C}\right)$ was $\sim 30$ minutes. Separation of the individual elements in both alloys was between 97.5 and 99.9\% (Table II). The total matrix removal of all of the elements in both matrices was $\sim 99.5 \%$. The highest element concentrations in the U-Al-Si and SILUMIN alloys were for uranium and aluminum, respectively. The extent of separation of these two major constituents was higher in comparison to the other minor constituents ( $\mathrm{Si}$ and $\mathrm{Ni}$ ). The possible reason for this higher fraction of separation of these major constituents could be due to the formation of strong fluoride complexes of the respective elements. After separation of the analytes, the concentration of the matrix elements in the sample solution in both matrices was well below their interference level, which was measured at the sensitive analytical wavelength of boron $(249.773 \mathrm{~nm})$.

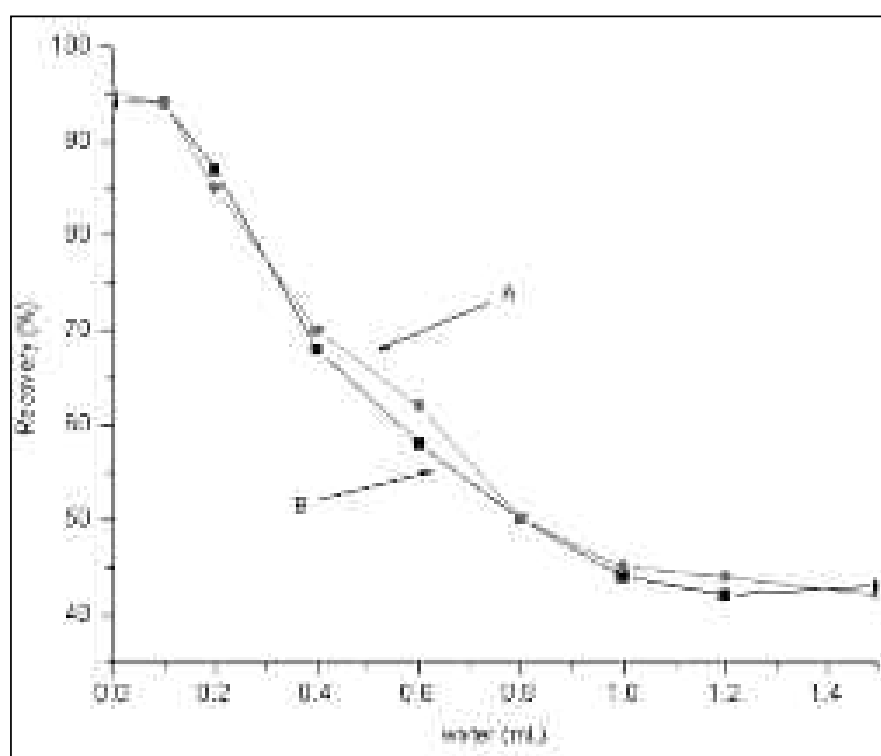

Fig. 1. The effect of water in the sample residue on the extraction efficiency of boron-mannitol complex into ethanol from (A) U-Al-Si and (B) SILUMIN alloys.

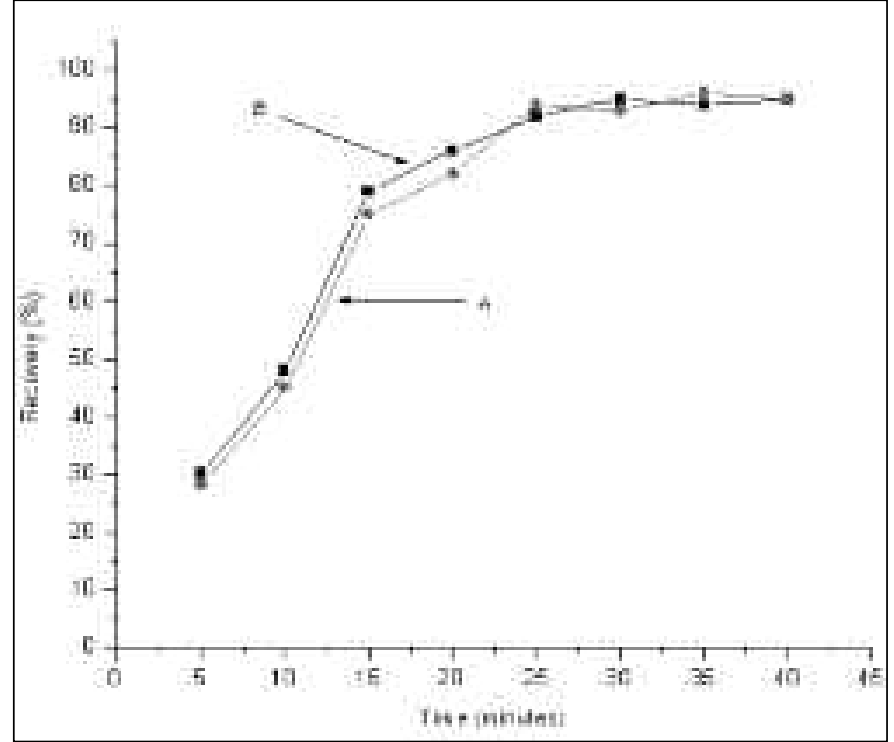

Fig. 2. The effect of time on the extraction of boron-mannitol complex from the sample residue into ethanol (A) U-Al-Si and (B) SILUMIN alloys. 
TABLE II

Separation of Individual Elements (\%) in U-Al-Si and SILUMIN Alloys

\begin{tabular}{clll}
\hline $\begin{array}{l}\text { Matrix } \\
\text { Elements }\end{array}$ & $\begin{array}{c}\text { Before Separation } \\
(\mathrm{mg})\end{array}$ & \multicolumn{1}{c}{$\begin{array}{c}\text { After Separation } \\
(\mathrm{mg})\end{array}$} & \multicolumn{1}{c}{$\begin{array}{c}\text { Separation } \\
(\%)\end{array}$} \\
\hline $\mathrm{U}$ & $144-148$ & $0.13-0.22$ & $99.8-99.9$ \\
$\mathrm{Al}$ & $44-50(168-172)$ & $0.76-0.60(0.48-0.52)$ & $97.8-98.5(99.4-99.7)$ \\
$\mathrm{Si}$ & $5.4-7.1(22-26)$ & $0.11-0.14(0.50-0.54)$ & $97.6-98.0(97.5-98.0)$ \\
$\mathrm{Ni}$ & $(3.7-4.1)$ & $(0.09-0.11)$ & $(96.7-97.5)$ \\
\hline
\end{tabular}

Around $0.2 \mathrm{~g}$ of sample was taken to study the extraction efficiency of matrix elements. Values given in the parentheses for SILUMIN matrix.

TABLE III

Determination of Boron in U-Al-Si and SILUMIN Alloys

\begin{tabular}{|c|c|c|}
\hline \multirow[t]{2}{*}{ Sample } & \multicolumn{2}{|c|}{ Boron Concentration $\left(\mathrm{mg} \mathrm{kg}^{-1} \pm \mathrm{s}\right)$} \\
\hline & $\begin{array}{c}\text { Present } \\
\text { Method }(n=5)\end{array}$ & $\begin{array}{l}\text { Spectrophotometric } \\
\text { Method (7) }\end{array}$ \\
\hline U-Al-Si-04 & $0.40 \pm 0.03$ & $0.39 \pm 0.01$ \\
\hline U-Al-Si-05 & $1.10 \pm 0.05$ & $1.05 \pm 0.03$ \\
\hline SILUMIN-1 & $2.7 \pm 0.1$ & - \\
\hline SILUMIN-2 & $2.9 \pm 0.1$ & - \\
\hline
\end{tabular}

TABLE IV

Recovery Study and Limit of Detection (LOD)

\begin{tabular}{ccccc}
\hline Sample (boron concentration) & $\begin{array}{c}\text { Boron } \\
\text { Added } \\
(\mathrm{ng})\end{array}$ & $\begin{array}{c}\text { Boron } \\
\text { Found } \\
(\mathrm{ng})\end{array}$ & $\begin{array}{c}\text { Boron } \\
\text { Recovery } \\
(\%)\end{array}$ & $\begin{array}{c}\text { LOD } \\
\left(\mathrm{mg} \mathrm{kg}^{-1}\right)\end{array}$ \\
\hline U-Al-Si-04 $\left(0.40 \pm 0.03 \mathrm{mg} \mathrm{kg}^{-1}\right)$ & 80 & 74.4 & 93 & \\
& 160 & 150.4 & 94 & 0.270 \\
SILUMIN-1 $\left(2.7 \pm 0.1 \mathrm{mg} \mathrm{kg}^{-1}\right)$ & 320 & 304 & 95 & \\
& 300 & 140 & 93 & \\
& 450 & 423 & 96 & 0.270 \\
\hline
\end{tabular}

Around $0.20 \mathrm{~g}$ of sample taken for recovery study.

${ }^{\mathrm{a}}$ boron found $=$ boron measured - boron concentration in the sample.

\section{Accuracy, Precision, and Recovery Study}

The analytical results obtained by the present method in the determination of boron in U-Al-Si alloy were compared with the spectrophotometric method (7) and are listed in Table III. It can be seen that the results from both methods are in good agreement. The student's $t$-test was applied to examine whether the results by the developed method and the existing spectrophotometric method differed significantly at the $95 \%$ confidence level. Since the calculated values of $t$ were less than the critical $t$ value of 2.776 (degrees of freedom $=4$ ), it follows that there is no statistically significant difference between the developed and the spectrophotometric results. Due to the lack of an alternative analytical method, method evalua- tion for SILUMIN matrix was carried out using a spike and recovery study. The recovery of boron in both matrices was found to be 93-96\% (Table IV).

There was no significant variation in the instrumental detection limit for pure solvent and process blank solutions. The method detection limit (3 s) was calculated based on 3 times the standard deviation of the process blank ( $\left.23 \pm 6 \mathrm{ng} \mathrm{mL}^{-1}, \mathrm{n}=5\right)$. Considering the dilution factor $(0.2 \mathrm{~g} \rightarrow 3.0 \mathrm{~mL})$, the detection limit in the solid sample was $0.270 \mu \mathrm{g} \mathrm{g}^{-1}$. The corresponding process blank (23 $\mathrm{ng} \mathrm{mL}^{-1}$ $\mathrm{x} 3 \mathrm{~mL} / 0.2 \mathrm{~g}$ ) value was $0.345 \mu \mathrm{g} \mathrm{g}^{-1}$. The relative standard deviation (RSD) was between 4-8\% at $0.40-2.9 \mathrm{mg} \mathrm{kg}^{-1}$ for both matrices.

\section{CONCLUSION}

The developed matrix separation procedure is a new, accurate, and precise method for the trace level determination of boron in two different types of important matrices (uranium-aluminum-silicon and aluminum-silicon-nickel alloys) found in the nuclear industry. The method is simple and about 10 samples can be handled at the same time, which makes it useful for routine sample analysis.

The very low process blank obtained from minimum use of reagents and less handling of the samples results in low detection limits. The limit of detection was found to be $0.270 \mathrm{mg} \mathrm{kg}^{1}$. The matrix removal was around 99.5\% and the recovery of boron for 80-450 ng was in the 93-96\% range. The analytical results of boron in U-Al-Si matrices (0.40-1.10 $\mathrm{mg} \mathrm{kg}^{-1}$ ) agreed well with existing spectrophotometric methods at $\pm 4 \%$ variation. 


\section{ACKNOWLEDGMENT}

The authors thankfully acknowledge the support and encouragement of Dr. T. Mukherjee, Director, and Dr. S.V. Narashiman, Ex-Associate Director, Chemistry Group, BARC.

Received September 21, 2011.

\section{REFERENCES}

1. L. I. Kolebneva, Metal Science and Heat Treatment 46/11-12, 474 (2004).

2. K. W. Puphal, J. A. Merrill, G. L. Booman and J. E. Rein, Anal. Chem. 30, 1612 (1958).

3. IAEA Nuclear Energy Series, No. NFT-4.6, Vienna, Aistroa (2009).

4. Y. D. Baranaev, V.V. Popov, V.N. Sharapov and V.M. Troyanov, J. Nucl. Mater. 319, 154 (2003).

5. T. Drglin and I. Naglic, Materiali in Technologije 37/6, 385 (2003).

6. D.C. Crawford, D.L. Porter and S.L. Hayes, J. Nucl. Mater. 371, 202 (2007).

7. P.S. Ramanjaneyulu, Y.S. Sayi and K.L. Ramakumar, J. Nucl. Mater. 378, 139 (2008).

8. R.N. Sah and P.H. Brown, Microchem. J. 56, 285 (1997).

9. S.Thangavel, S. M. Dhavile, K. Dash and S. C. Chaurasia, Anal. Chim. Acta 502, 265 (2004).

10. P. Carrero, A. Malave, E. Rojas, C. Rondon, Y. P. de Pena, J. L. Burguera and M. Burguera, Talanta 68, 374 (2005).

11. S. Kozono, M. Yagi and R. Takashi, Anal. Chim. Acta 368, 275 (1998).

12. S. Marin, S. Cornejo, C. Jara and N. Duran, Fresenius J. Anal. Chem. 355, 680 (1996).

13. E. H. van Veen, M. T. C. de LoosVollebregt, A. P. Wassink, and $\mathrm{H}$. Kalter, Anal. Chem. 64, 1643 (1992).

14. M. Oshima, S. Motomizu and K. Toei, Anal. Chem. 56, 948 (1984).

15. K. R. Betty and G. T. Day, Analyst 111, 455 (1986)
16. D.A. Johnson, D.D. Siemer and W.F. Bauer, Anal. Chim. Acta 270, 223 (1992).

17. A. Lopez Molinero, A. Ferrer and J.R. Castillo, Talanta 40, 1397 (1993).

18. A. Townshend (Ed.), Encyclopedia of Analytical Science, Vol. 1, Academic press, London, U.K. (1995).

19. F.D. Snell and L.S. Ettre, Encyclopedia of Industrial Chemical Analysis, Vol. 17, Interscience Publishers, USA (1973).

20. C. Feldman, Anal. Chem. 33, 1916 (1961).

21. T. Ishikawa and E. Nakamura, Anal. Chem. 62, 2612 (1990).

22. M. D'Orazio, Geostand. Geoanal. Res. 23, 21(1999).

23. D. Karunasagar, K. Dash and K. Chandrasekaran, At. Spectrosc. 21/6, 216 (2000).

24. P.S. Ramanjaneyulu, Y.S. Sayi, V.A. Raman and K.L.Ramakumar, J. Radioanal. Nucl. Chem. 274, 109 (2007). 